DOI: https://doi.org/10.47405/mjssh.v6i8.912

\begin{tabular}{|c|c|}
\hline 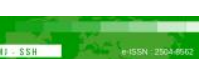 & Malaysian Journal of Social Sciences and Humanities (MJSSH) \\
\hline Malaysian Journal of & Volume 6, Issue 8, August 2021 \\
\hline (Mu-ssH) & e-ISSN : 2504-8562 \\
\hline & $\begin{array}{l}\text { Journal home page: } \\
\text { www.msocialsciences.com }\end{array}$ \\
\hline
\end{tabular}

\title{
Pembangunan Profesionalisme Guru Matematik Sekolah Rendah: Kajian Literatur Bersistematik
}

\author{
Shamsinar Jamaludin ${ }^{1}$, Roslinda Rosli ${ }^{1}$ \\ 1Fakulti Pendidikan, Universiti Kebangsaan Malaysia (UKM) \\ Correspondence: Roslinda Rosli (roslinda@ukm.edu.my)
}

\begin{abstract}
Abstrak
Isu utama dalam dunia pendidikan yang semakin mencabar ketika ini telah menuntut guru melakukan perubahan secara keseluruhan dari pelbagai aspek. Ini termasuklah cabaran yang menguji kemahiran, kemampuan dan kekuatan guru dalam melakukan sesuatu aktiviti. Setiap perubahan yang berlaku dalam kurikulum memerlukan guru meneliti secara terperinci agar perubahan yang dilakukan dapat memberi manfaat kepada semua. Tujuan kajian adalah untuk mensintesis kajian empirikal tentang isu-isu dan kritikan yang berkaitan dengan pembangunan profesionalisme dalam kalangan guru matematik sekolah rendah. Kajian literatur bersistematik adalah satu lagi kajian yang wujud untuk mengenal pasti secara kritis perubahan dan perbezaan dapatan empirikal terhadap satu-satu aspek yang ingin dikaji. Kajian tinjauan merupakan reka bentuk yang dijalankan untuk mensintesis dapatan penyelidikan empirikal yang berkaitan dengan pembangunan profesionalisme guru matematik sekolah rendah. Hasil daripada dapatan analisis kajian empirikal terpilih, kajian terhadap STEM dan lesson study menjadi pilihan pengkaji dalam pembangunan profesionalisme guru matematik sekolah rendah. Manakala Amerika Syarikat merupakan negara yang tertinggi menjalankan kajian ini. Faktor masa, keperluan guru dan kesan terhadap pencapaian pelajar menjadi pengaruh utama dalam pemantapan pembangunan profesionalisme kepada guru matematik sekolah rendah. Secara kolektif, penganjuran sesuatu program perlu dilihat dalam perbagai aspek agar objektif dan sasaran sampai kepada matlamat utama. Implikasi dapatan kajian ialah program pembangunan profesionalisme ini harus berterusan sepanjang tahun dan bukannya dalam sesi singkat. Hal ini kerana, sesi ringkas terbukti kurang berkesan dalam mengubah sikap guru terhadap pengajaran dalam bilik darjah. Program pembangunan profesionalisme ini juga harus diadakan di sekolah supaya semua guru matematik dapat mengikuti program tersebut, dan bukannya sebilangan kecil guru sahaja.
\end{abstract}

Kata kunci: Pembangunan profesionalisme, guru matematik, sekolah rendah, kajian literatur bersistematik

\section{Primary School Mathematics Teacher's Professional Development: A Systematic Literature Review}

\begin{abstract}
The current challenging issue in education world require teachers to totally change in various aspect. This includes skills, capability and strength in conducting activities. Any changes in curriculum need to be reviewed accordingly so that it can be beneficial holistically. The purpose of this study is to synthesis empirically the issues and critism in relation to the professional development among mathematics
\end{abstract}


teachers in primary school. Systematic literature study is another study available to identify changes and differences of the empirical finding on certain aspect need to be find out. Literature review was designed to synthesis the finding from empirical research which relate to the professional development among mathematic teachers in primary school. The finding from selected empirical research analysis found that STEM and lesson study become a main researcher's choices in professional development among mathematic teachers in primary school. Meanwhile United State of America is the highest country conducting this research. Time, teacher's need, and the effect of student achievement are major factors that contribute to the professional development among mathematic teacher in primary school. Collectively, the organizing any related programme need to be seen in various aspect to ensure the desired aim and objective can be achieved. The implication of the study is that the professional development programme needs to be conducted continuously and not in a short-term session. This because, short term session was not effective in changing the teacher's behaviour and characteristic toward teaching delivery in classroom. The professional development programme also needs to be conducted in school to ensure all mathematic teacher join the programme.

Keywords: Professional development, mathematic teacher, primary school, systematic literature review

\section{Pengenalan}

Pembangunan profesionalisme adalah merupakan aktiviti latihan dalam perkhidmatan untuk pendidik meningkatkan pembelajaran murid dengan melibatkan diri dalam satu aktiviti dan proses yang dirancang bagi memperkaya serta mengembangkan kemahiran pengetahuan profesionalisme mereka. Pembangunan profesionalisme ini amat penting kerana kerjaya ini dianggap sebagai profesion yang sukar dan kritikal (Sabbah et al., 2020).

Oleh itu, program pembangunan profesionalisme guru telah digubal dalam Pelan Induk Pembangunan Pendidikan 2013-2025 untuk meningkatkan profesion keguruan menerusi peningkatan kualiti, kerjaya dan kebajikan guru (KPM 2020). Dalam Laporan Kebangsaan TIMSS 2019, menyatakan keperluan pembangunan profesionalisme guru matematik berkaitan menambah baik kemahiran berfikir atau kemahiran penyelesaian masalah dan mengintegrasikan teknologi maklumat dalam matematik adalah agak tinggi iaitu 77\%. Bagi latihan yang lain, 70\% keperluan latihan adalah seperti berikut pedagogi matematik, kurikulum dan kandungan matematik (60\%), pentaksiran matematik (67\%), dan latihan pembangunan profesional untuk menangani keperluan individu murid (72\%). Justeru, guru perlu memenuhi keperluan ini dengan melibatkan diri dalam pembangunan profesionalisme.

Menurut Mary (2016), hasil pembangunan profesionalisme ini bermanfaat bagi guru-guru yang berminat dalam inovasi khususnya dalam pendidikan matematik peringkat awal. Konsep matematik perlu asas yang mantap agar tahap kognitif murid dapat dicapai untuk kemahiran yang seterusnya. Sehubungan dengan itu, guru yang kreatif dan inovatif amat diperlukan supaya proses pengajaran dapat disampaikan dengan tarikan yang mantap. Proses ini memerlukan masa dan tenaga. Namun, latihan dan pembangunan guru dikatakan kurang berkesan kerana dipengaruhi oleh pelbagai faktor seperti beban kerja, karenah birokrasi dan pengaruh politik. Guru-guru berpendapat bahawa pembangunan profesionalisme berterusan adalah penting dalam meningkatkan keberkesanan pengajaran (Rusliza et al., 2017). Pernyataan ini disokong oleh Alias (2017), guru-guru perlu meningkatkan kualiti diri dari semasa ke semasa dengan mengikuti pembangunan profesionalisme guru. Guru yang berkualiti mestilah sentiasa peka dengan setiap perubahan yang berlaku dalam sistem pendidikan negara.

Rentetan itu, kajian ini dijalankan untuk meninjau jenis pembangunan profesionalisme guru matematik sekolah rendah serta elemen-elemen yang telah dilaksanakan pada perspektif kajian-kajian tertentu yang disusun dan dipersembahkan dalam kajian sorotan literatur. Selain itu, jenis-jenis program pembangunan profesionalisme yang telah dirancang untuk guru matematik sekolah rendah juga dapat dikenal pasti. Perbincangan seterusnya merangkumi empat bahagian, iaitu (1) literatur berkaitan, (2) metodologi 
kajian, (3) dapatan kajian dan (4) perbincangan dapatan kajian yang dituruti dengan kesimpulan dan cadangan kajian lanjutan.

\section{Sorotan Literatur}

Istilah pembangunan profesionalisme guru sering kali dikaitkan dengan pembangunan staf atau pembangunan profesional. Menurut Muhammad Faizal et al. (2016), sebelum ini, bidang keguruan menggunakan istilah "pembangunan staf" atau "latihan dalaman" yang dikaitkan dengan bengkel atau kursus jangka pendek. Tambah mereka lagi, istilah tersebut melibatkan proses pencambahan maklumat baharu dalam bidang yang berkaitan dengan kerjaya guru. Mereka menerima ilmu tersebut dan mengamalkannya dalam pekerjaan seharian. Pembangunan profesionalisme yang berkesan adalah sebagai pembelajaran profesional berstruktur yang menghasilkan perubahan dalam amalan guru dan peningkatan hasil pembelajaran pelajar (Darling-Hammond et al., 2017). Pernyataan ini disokong oleh Ansyari et al. (2020), bahawa pembangunan profesionalisme terhadap guru berpotensi memberi kesan yang baik terhadap pelajar. Bahkan, kepentingan menggabungkan ciri-ciri pembangunan profesional yang berkesan dapat meningkatkan disiplin, efikasi dan kepuasan guru dalam menyampaikan pengajaran. Secara teori, bimbingan profesional harus menjadi model pembangunan yang berkesan, hal ini kerana, pembimbing kerap dapat bertemu dengan guru yang dibimbing sepanjang tahun persekolahan. Guru akan diberi bimbingan dalam penyampaian pengajaran serta diberi bantuan secara khusus terhadap masalah dan cabaran yang mereka hadapi (Harbour \& Saclarides, 2020). Justeru, pembangunan profesionalisme menurut Harbour dan Saclarides (2020) dan Muhammad Faizal et al. (2016) lebih cenderung kepada implikasi kepada kualiti guru. Manakala Ansyari et al. (2020) dan Darling-Hammond et al. (2020) pula menggariskan bahawa pembangunan profesionalisme yang diterima oleh guru bukan sahaja dapat menambahbaikkan amalan mereka malah memberi impak yang positif kepada pelajar di sekolah.

Pengetahuan untuk menyampaikan pengajaran dan praktis mempunyai pengaruh yang penting terhadap pembelajaran pelajar. Terdapat bukti penyelidikan mengenai peranan penting kedua-dua pengetahuan kandungan matematik dan pengetahuan kandungan pedagogi untuk pencapaian pelajar dalam matematik (Teresa, Rodriguez \& Reckase, 2020). Menurut Shulman (1987), pengetahuan pedagogi isi kandungan atau PPIK ialah sejenis pengetahuan yang unik bagi seseorang guru yang mana guru perlu mengaitkan pengetahuan pedagogi (pengetahuan mengenai cara mengajar) yang ada pada dirinya dengan pengetahuan isi kandungan (apa yang perlu diajar) kepada muridnya. Shulman (1987) juga menyatakan PPIK adalah sangat unik sehingga ianya dapat membezakan antara guru pakar dengan pakar dalam bidang yang tidak mempunyai pengalaman mengajar. Pengetahuan pedagogi dan isi kandungan (PPIK) juga mementingkan kefahaman guru terhadap pengetahuan isi kandungan yang disampaikan kepada pelajar, keupayaan guru dalam mempelbagaikan kaedah pengajaran agar mudah difahami pelajar serta kefahaman terhadap ciri-ciri dan kebolehan pelajar (Shulman, 1987). Hal ini bermakna PPIK (Shulman, 1987; Teresa, Rodriguez \& Reckase, 2020) penting agar guru dapat menterjemahkan kandungan pelajaran dengan mengubahsuaikannya mengikut pengetahuan sedia ada, minat dan kebolehan pelajar agar isi pelajaran mudah dikuasai pelajar.

Jacob et al. (2017) mendapati bahawa, sebelum guru menyertai program pembangunan profesionalisme, tahap pengetahuan matematik mereka agak rendah untuk mengajar. Dalam pada itu, walaupun para guru mungkin bersikap positif tentang pengalaman mereka, kandungan dan strategi matematik yang disusun dalam program pembangunan profesionalisme mungkin melebihi tahap pengetahuan dan kemahiran semasa beberapa orang guru, lantas menjadikannya sukar untuk melaksanakan strategi yang dicadangkan dengan berkesan. Jelaslah bahawa, kandungan program pembangunan profesionalisme yang dirangka cukup untuk mengubah sistem kepercayaan guru mengenai pengajaran seperti yang ditunjukkan melalui tindak balas tinjauan guru dan sejauh mana skor tahap pengetahuan isi kandungan mereka, namun tidak mencukupi dari segi penyediaan alat dan sokongan untuk menerapkan kepercayaan tersebut di dalam kelas mereka (Jacob et al., 2017). Perubahan yang ketara hanya dapat terjadi apabila guru memiliki pola pemikiran, bahkan juga bahan dan sokongan berterusan untuk melaksanakan apa yang telah mereka pelajari. Selain itu, kita juga dapat menyimpulkan bahawa guru matematik sekolah rendah memperoleh kemahiran dalam pendidikan STEM melalui pembangunan profesionalisme dengan peningkatan kemahiran abad ke-21 (Aydin, 2020). Dapatan ini disokong dalam kajiannya mengenai persepsi guru 
sekolah rendah sebelum pengajaran STEM dilaksanakan. Tahap keyakinan yang rendah, kekurangan pengetahuan isi kandungan dan kurang kemahiran teknologi komputer menjadi masalah utama. Namun, bukti daripada dapatan temu bual dan catatan buku harian guru, melalui latihan dalam program intervensi, persepsi negatif mereka dapat dihilangkan, mereka merasa santai, dan keyakinan mereka berkembang, apa yang paling penting, mereka dapat mengintegrasikan teknologi dalam kelas. Justeru, Aydin (2020); Jacob et al. (2017) bersetuju menggariskan bahawa pembangunan profesionalisme ini dapat mengubah kepercayaan dan efikasi guru dalam bidang kemahiran, pengetahuan serta amalan mereka di dalam kelas.

Tambahan pula, pembangunan profesionalisme ini mempunyai implikasi penting terhadap kualiti guru (Sharp, Bonjour \& Cox, 2019). Walau bagaimanapun, terdapat satu masalah kritikal dengan set andaian yang kurang diberi perhatian dalam penyelidikan program pembangunan profesionalisme guru, di mana harapan agar peningkatan pengetahuan guru dapat diteruskan dan memberi kesan terhadap pengajaran (Liu \& Phelps, 2020). Hasil kajiannya menunjukkan bahawa pengetahuan guru matematik sekolah rendah tidak stabil selepas menyertai program pembangunan profesionalisme. Sebenarnya, kehilangan pengetahuan, ketirisan atau kemerosotan pengetahuan, memang berlaku. Tujuan utama pembangunan profesionalisme guru adalah untuk meningkatkan prestasi pelajar, namun fokus program ini bukan sahaja tertumpu pada apa yang dipelajari oleh guru tetapi juga harapan supaya pembelajaran itu dapat diterjemahkan semula di dalam kelas secara berterusan. Maka, pembangunan profesionalisme guru adalah proses sosial (Bandura, 1977), yang ditingkatkan oleh struktur dan cara operasi pelajaran, ia memberikan pembelajaran yang signifikan mengenai pengajaran Matematik dan juga pengembangan aspek penting budaya profesional.

\section{Metod Kajian}

Kajian mengenai pembangunan profesionalisme guru matematik sekolah rendah dianalisis menggunakan kaedah sorotan literatur bersistematik atau dikenali sebagai Systematic Literature Review (SLR). Dalam kajian ini, lapan tahap kaedah SLR dilaksanakan iaitu (1) merumuskan masalah penyelidikan; (2) mengembangkan dan mengesahkan protokol kajian; (3) mencari literatur; (4) pemeriksaan untuk kemasukan; (5) menilai kualiti; (6) mengekstrak data; (7) menganalisis dan mensintesis data; dan (8) melaporkan dapatan seperti yang dicadangkan oleh Xiao dan Watson (2019).

\section{Langkah 1: Merumuskan masalah penyelidikan}

Menurut Eva (2018), persoalan kajian mendorong keseluruhan proses tinjauan literatur. Pemilihan kajian untuk dimasukkan ke dalam tinjauan, pengekstrakan dan sintesis data, serta pelaporan, harus menjurus untuk menjawab persoalan kajian. Persoalan kajian bagi kajian ini adalah :1. Apakah pembangunan profesionalisme guru matematik sekolah rendah dengan menggunakan kajian empirikal? 2. Apakah elemen-elemen penyelidikan empirikal berkaitan pembangunan profesionalisme guru matematik sekolah rendah? Oleh itu, kajian ini memerlukan proses pencarian artikel atau kajian empirikal yang sistematik supaya sampel artikel yang diperoleh dapat menghuraikan persoalan kajian serta memiliki kaedah penyelidikan dan ciri-ciri yang bertepatan dengan kriteria kajian yang telah ditetapkan.

\section{Langkah 2: Mengembangkan dan mengesahkan protokol kajian}

Langkah ini adalah untuk menentukan kaedah yang digunakan dalam menjalankan tinjauan (Xiao \& Watson, 2019). Selain itu, ia dapat mengurangkan bias di kalangan penyelidik dan pada yang sama ia dapat meningkatkan kebolehpercayaan tinjauan oleh pihak lain. Semua artikel yang dipilih akan dibaca dengan teliti. Maklumat mengenai pengarang, tajuk kajian, tahun pengarang artikel diterbitkan, objektif kajian, sampel dan dapatan direkodkan secara sistematik dalam borang pengekodan (coding sheet).

\section{Langkah 3: Mencari literatur}


Pangkalan data elektronik digunakan untuk mencari artikel yang berkaitan dengan bidang pendidikan matematik dan sains sosial. Pada masa kini, pangkalan data elektronik adalah menjadi pilihan utama dalam pencarian literatur (Xiao \& Watson, 2019). Tinjauan dalam kajian ini dilakukan bergantung kepada dua pangkalan data jurnal utama, iaitu Scopus dan Web of Science (WoS). Menurut Mohd Kusnan, Tarmuji dan Omar (2020), pangkalan data WoS dianggap sebagai pangkalan data yang kukuh, yang terdiri daripada kira-kira 250 disiplin ilmu termasuk bidang subjek sains, sains sosial, dan seni dan kemanusiaan dengan lebih dari 34,000 jurnal. Ditubuhkan oleh Clarivate Analytics, ia terdiri daripada lebih dari 118 tahun fail belakang dan 161 juta rekod data. Sebaliknya, Scopus adalah pangkalan data abstrak dan kutipan terbesar dari literatur yang telah disemak dan digunakan oleh lebih daripada 3,000 buah institusi akademik, kerajaan dan korporat di seluruh dunia. Scopus terdiri daripada jurnal ilmiah, buku dan prosiding persidangan yang berkaitan dengan sains sosial, alam sekitar, pertanian, dan biologi. Rentetan carian artikel adalah seperti dalam Jadual 1. Seterusnya, kata kunci untuk carian harus diambil dari persoalan kajian. Oleh itu, Boolean operator digunakan untuk proses pencarian.

Jadual 1: Rentetan carian

Pangkalan Data Scopus

TITLE-ABS-KEY ((“PROFESSIONAL DEVELOPMENT" AND "MATHEMATICS “AND "PRIMARY SCHOOL” OR "ELEMENTARY SCHOOL"))

Web of Science TS=((“PROFESSIONAL DEVELOPMENT" AND

"MATHEMATICS “AND "PRIMARY SCHOOL” OR

"ELEMENTARY SCHOOL”))

\section{Langkah 4: Pemeriksaan untuk kemasukan}

Setelah menyusun senarai kriteria pencarian, setiap artikel ditapis untuk menentukan sama ada ia layak diambil untuk pengekstrakan dan dianalisis. Terdapat dua peringkat dalam langkah ini, peringkat pertama adalah dengan menapis secara kasar artikel berdasarkan tinjauan abstrak dan peringkat kedua adalah dengan tapisan kualiti yang halus melalui penilaian berdasarkan tinjauan teks penuh (Rajah 1). Tujuan penyaringan awal ini adalah untuk menyingkirkan artikel dengan kandungan yang tidak menepati persoalan kajian dan kriteria yang ditetapkan.

\section{Langkah 5: Menilai kualiti}

Seperti yang disebutkan dalam Xiao dan Watson (2019), tujuan penilaian mutu adalah untuk memperbaiki artikel teks penuh kerana ini adalah proses terakhir dalam penyediaan kumpulan kajian untuk pengekstrakan data dan sintesis. Oleh itu, rubrik yang diadaptasi dari Margot dan Kettler (2019) telah digunakan. Rubrik ini meneliti tujuh (7) kriteria iaitu (1) Objektif dan Tujuan, (2) Ulasan Literatur, (3) Kerangka Teoritis atau Konseptual, (4) Peserta, (5) Kaedah, (6) Hasil dan Kesimpulan dan (7) Kepentingan. Setiap kriteria dijaringkan pada skala 4 mata di mana $1=$ Tidak Memenuhi Standard, $2=$ Hampir Memenuhi Standard, $3=$ Memenuhi Standard dan $4=$ Melebihi Piawaian. Setelah menjumlahkan tujuh (7) bahagian, diartikulasikan dengan skor sama atau kurang daripada 14 dikecualikan kerana tidak memenuhi standard kualiti. Setelah menilai kualiti setiap artikel, hanya 18 artikel melepasi penilaian.

\section{Langkah 6: Mengekstrak data}

Kaedah sintesis akan memandu proses pengekstrakan data (Xiao \& Watson, 2019). Secara amnya, proses pengekstrakan data akan kerap berlaku melibatkan pengekodan, terutama untuk memanjangkan ulasan. Maklumat mengenai pengarang, tajuk kajian, tahun pengarang artikel diterbitkan, objektif kajian, sampel dan dapatan direkodkan secara sistematik dalam borang pengekodan (coding sheet).

\section{Langkah 7: Menganalisis dan mensintesis data}


Setelah proses pengekstrakan data selesai, data akan disusun mengikut tinjauan yang telah dipilih. Selalunya, ini adalah beberapa kombinasi carta, jadual, dan penerangan teks, walaupun setiap jenis ulasan akan ada standard pelaporan yang sedikit berbeza. Maklumat mengenai pengarang, tajuk kajian, tahun pengarang artikel diterbitkan, objektif kajian, sampel dan dapatan direkodkan secara sistematik dalam bentuk jadual sekali lagi. Seterusnya, ia akan dirujuk untuk cadangan bagaimana melakukan tinjauan khusus.

\section{Langkah 8: Melaporkan dapatan kriteria kemasukan dan pengecualian dinyatakan secara terperinci dalam langkah ini}

Rajah 1: Carta alir pemilihan sampel kajian

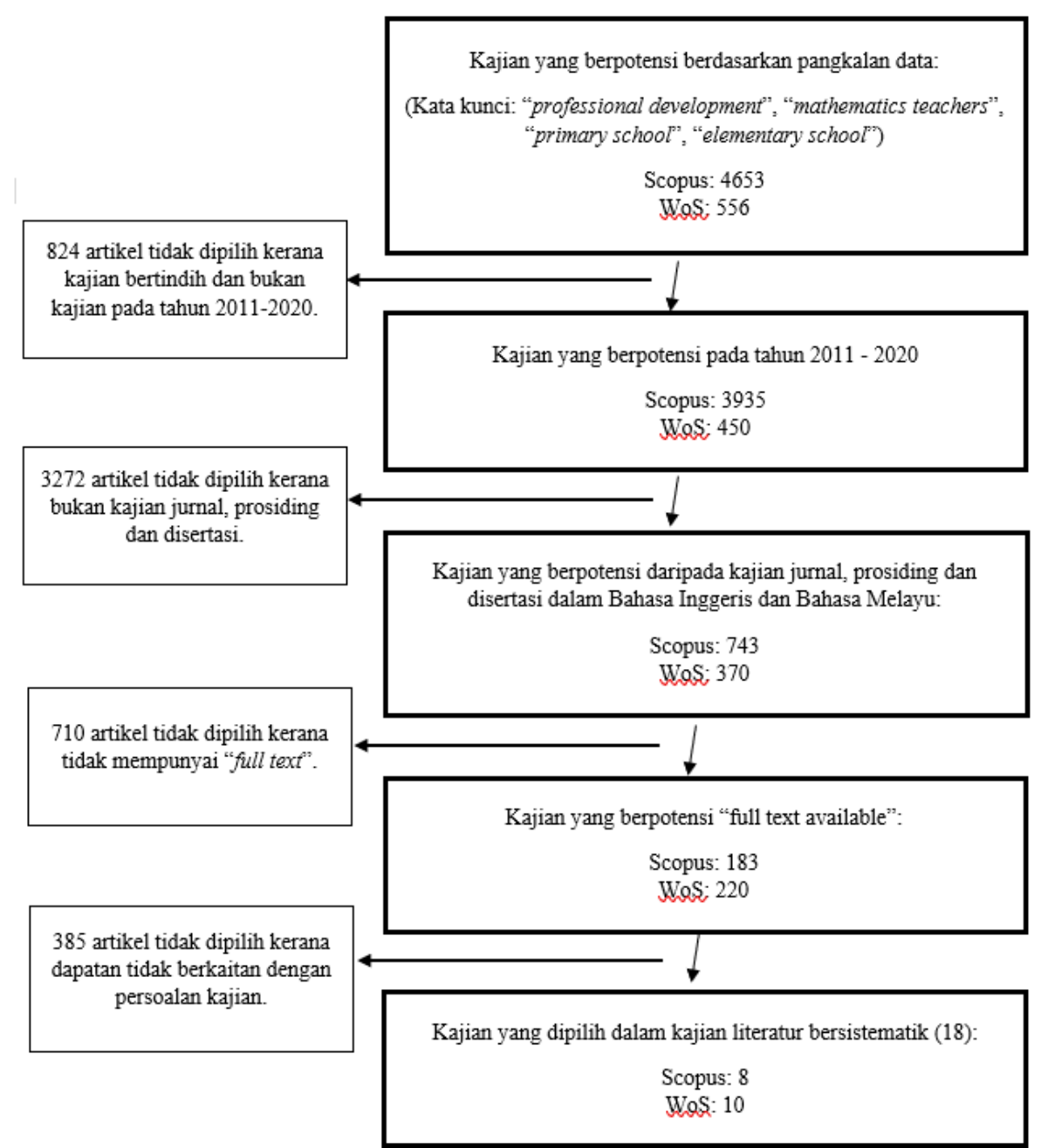

\section{Hasil Kajian}

\section{Aktiviti pembangunan profesionalisme}

Tinjauan literatur bersistematik ini memberikan perbandingan berkaitan aktiviti yang dikaji oleh 18 kajian empirikal yang terpilih kepada sembilan aktiviti yang berbeza iaitu STEM, lesson study, penggunaan model, teknologi, bengkel matematik, PLC, peranan pakar matematik dalam pembangunan profesionalisme, refleksi guru terhadap pembangunan profesionalisme dan keperluan pembangunan profesionalisme guru berkaitan kemahiran matematik. 
Jadual 2: Perbandingan aktiviti pembangunan profesionalisme yang digunakan dalam kajian literatur

\begin{tabular}{|c|c|c|}
\hline Aktiviti & Bilangan kajian & Kajian \\
\hline STEM & 4 & $\begin{array}{l}\text { Baker \& Galanti (2017), } \\
\text { Aldahmash et al. (2019), Aydin } \\
\text { (2020), Estapa \& Tank (2017) }\end{array}$ \\
\hline Lesson study & 4 & $\begin{array}{l}\text { Takahashi \& McDougal (2016), } \\
\text { Robutti et al. (2016), Warwick et } \\
\text { al. (2016), Alamri (2020) }\end{array}$ \\
\hline Penggunaan Model & 2 & $\begin{array}{l}\text { Viseu, Martins \& Leite (2020), } \\
\text { Fulton et al. (2019) }\end{array}$ \\
\hline Teknologi & 2 & $\begin{array}{l}\text { Hansen, Mavrikis \& Geraniou } \\
\text { (2016), Thurm \& Barzel (2020) }\end{array}$ \\
\hline Bengkel Matematik & 1 & Sharp, Bonjour \& Cox (2019) \\
\hline PLC & 1 & Miller et al. (2019) \\
\hline $\begin{array}{l}\text { Peranan pakar matematik dalam } \\
\text { pembangunan profesionalisme }\end{array}$ & 1 & Hjalmarson \& Baker (2020) \\
\hline $\begin{array}{l}\text { Refleksi guru terhadap } \\
\text { pembangunan profesionalisme }\end{array}$ & 2 & Biccard (2019), Saad et al. (2018) \\
\hline $\begin{array}{l}\text { Keperluan pembangunan } \\
\text { profesionalisme guru berkaitan } \\
\text { kemahiran matematik }\end{array}$ & 1 & Barham (2020) \\
\hline
\end{tabular}

Objektif pertama tinjauan literatur bersistematik ini juga meninjau aktiviti pembangunan profesionalisme guru matematik sekolah rendah dalam kajian empirikal. Hasil daripada dapatan analisis kajian empirikal terpilih, kajian terhadap STEM dan lesson study menjadi pilihan pengkaji dalam pembangunan profesionalisme guru matematik sekolah rendah. Kajian-kajian terdiri daripada pelbagai latar belakang negara. Dalam pada itu, terdapat juga aktiviti penggunaan model, teknologi dan juga refleksi guru matematik sekolah rendah terhadap pembangunan profesionalisme yang dilaksanakan. Seterusnya, kajian empirikal yang dilaksanakan mengenal pasti tahap keberkesanan pembangunan profesionalisme ke atas guru mengikut perspektif pelajar dari pelbagai latar belakang yang berbeza.

Merujuk kepada analisis menegak, negara kajian terangkum untuk menjawab persoalan kajian yang pertama. Jadual 3 di bawah menunjukkan analisis tinjauan literatur mengenai negara kajian dalam pembangunan profesionalisme guru matematik sekolah rendah.

Jadual 3: Negara kajian

\begin{tabular}{ccc}
\hline Negara kajian & Bilangan & \multicolumn{1}{c}{ Kajian } \\
\hline Australia & 1 & Miller et al. (2019) \\
Qatar & 1 & Barham (2020)
\end{tabular}


Amerika Syarikat

Malaysia

Afrika Selatan

United Kingdom

Jerman

Portugal

Arab Saudi

Turki

Lain-lain
Estapa \& Tank (2017), (Baker \& Galanti 2017), (Takahashi \& McDougal 2016), Fulton et al. (2019), Sharp, Bonjour \& Cox (2019)

Saad et al. (2018)

Biccard (2019)

Hansen et al. (2016), Warwick et al. (2016)

Thurm \& Barzel (2020)

Viseu, Martins \& Leite (2020)

Aldahmash et al. (2019), Alamri (2020)

Aydin (2020)

Robutti et al. (2016),

Hjalmarson \& Baker (2020)

Dapatan secara jelas menunjukkan majoriti kajian telah dijalankan di negara Amerika Syarikat. Manakala United Kingdom, Arab Saudi dan lain-lain diwakili dengan dua kajian dan selebihnya satu kajian dari negara Australia, Qatar, Malaysia, Afrika Selatan, Jerman, Portugal dan Turki.

\section{Elemen-elemen berkaitan pembangunan profesionalisme.}

Instrumen kajian menggunakan temu bual menjadi pilihan kebanyakan pengkaji dalam bidang pembangunan profesionalisme guru matematik sekolah rendah ini. Berdasarkan analisis yang dijalankan, temu bual yang digunakan adalah untuk mengukur sejauh mana kecenderungan guru untuk memilih bahan dalam penggunaan teknologi di bilik darjah (Hansen et al., 2016). Selain itu, instrumen kajian ini turut digunakan untuk mengetahui perasaan dan tahap minat guru terhadap penggunaan Lesson study yang digunakan contohnya kajian oleh Alamri (2020).

Tinjauan literatur bersistematik ini turut mengumpul data berkaitan kaedah metodologi yang digunakan bagi setiap kajian empirikal terpilih. Berdasarkan Jadual 4.3, majoriti daripada set data iaitu sebanyak 11 buah kajian telah menggunakan kaedah kualitatif dalam kajian mereka berkaitan pembangunan profesionalisme guru matematik sekolah rendah. Kajian-kajian ini tertumpu pada negara-negara seperti Turki, Afrika Selatan, Jerman, Amerika Syarikat, Portugal dan United Kingdom (Jadual 4). Seterusnya, 4 kajian lain menggunakan kaedah kuantitatif. Hanya 3 kajian empirikal yang menggunakan kaedah gabungan kuantitatif dan kualitatif yang masing-masing dari negara Amerika Syarikat, Australia dan Arab Saudi (Jadual 4).

Jadual 4: Kaedah pengumpulan data

\begin{tabular}{lcccccc}
\hline \multicolumn{1}{c}{ Kajian } & n & $\begin{array}{c}\text { Soal } \\
\text { selidik }\end{array}$ & Temu bual & $\begin{array}{c}\text { Analisis } \\
\text { dokumen }\end{array}$ & Pemerhatian & Ujian \\
\hline Biccard (2019) & 5 & & $\mathrm{x}$ & & $\mathrm{x}$ & \\
Aydin (2020) & 5 & & $\mathrm{x}$ & & $\mathrm{x}$ & \\
Hjalmarson \& & & & & $\mathrm{x}$ & & \\
Baker (2020) & & & & &
\end{tabular}


Robutti et al.

(2016)

Sharp, Bonjour \& 8

$\mathrm{x}$

$\mathrm{X}$

X $\quad \mathrm{X}$

Cox (2019)

Fulton et al.

28

$\mathrm{x}$

$\mathrm{X}$

(2019)

Takahashi \&

5

McDougal

(2016)

Baker \&

Galanti (2017)

Estapa \& Tank

(2017)

Miller et al.

(2019)

Barham (2020)

$30 \quad \mathrm{x} \quad \mathrm{x} \quad \mathrm{x}$

Alamri (2020)

$\mathrm{X}$

$\mathrm{X}$

Aldahmash et

al. (2019)

Viseu, Martins

\& Leite (2020)

Hansen,

Mavrikis \&

Geraniou

(2016)

Warwick et al.

(2016)

Saad et al.

Thurm \&

Analisis terhadap persoalan kajian yang kedua mengenai elemen-elemen yang berkaitan pembangunan profesionalisme guru matematik sekolah rendah mendapati terdapat 5 skop kajian yang dijalankan oleh 18 kajian empirikal terpilih (Jadual 5).

Jadual 5 Skop kajian empirikal

\begin{tabular}{lcl}
\hline \multicolumn{1}{c}{ Skop Kajian Empirikal } & Bilangan Kajian & \multicolumn{1}{c}{ Kajian } \\
\hline Pengajaran & 7 & $\begin{array}{l}\text { Saad et al. (2018), Warwick et al. } \\
(2016), \text { Biccard (2019), Alamri (2020), } \\
\text { Viseu, Martins \& Leite (2020), Sharp, } \\
\text { Bonjour \& Cox (2019), Miller et al. } \\
(2019)\end{array}$ \\
$\begin{array}{l}\text { Fulton et al. (2019) } \\
\text { Profesionalisme keguruan }\end{array}$ & 1 & $\begin{array}{l}\text { Robutti et al. (2016), Takahashi \& } \\
\text { McDougal (2016), Hjalmarson \& Baker } \\
\text { profesionalisme }\end{array}$ \\
& 5 & $\begin{array}{l}\text { (2020), Barham (2020), Thurm \& } \\
\text { Barzel (2020) }\end{array}$
\end{tabular}


STEM

Teknologi
4
Aydin (2020), Estapa \& Tank (2017), Aldahmash et al. (2019), Baker \& Galanti (2017)

Hansen, Mavrikis \& Geraniou (2016)

Berdasarkan dapatan yang diperoleh, beberapa kajian empirikal (Fulton et al., 2019; Miller et al., 2019; Biccard, 2019) dikelaskan kepada lebih daripada satu skop kajian mengikut tujuan kajian tersebut dijalankan. Menurut Fulton (2019), ketika guru membuat tugasan pemodelan dengan nilai-nilai di minda, pemodelan memberi peluang kepada semua pelajar menggunakan matematik untuk menyelesaikan masalah yang penting bagi mereka dengan cara memupuk dan memberi manfaat kepada masyarakat. Ini jelas menunjukkan bahawa selain melihat kepentingan aktiviti pemodelan matematik kepada guru dan pelajar, impak kepada masyarakat juga dinilai dari segi relevan dan mudah diakses. Kajian ini telah dijalankan kepada guru matematik sekolah rendah di Amerika Syarikat (Jadual 3) yang sudah pasti untuk memberi penekanan kepada pengetahuan isi kandungan dan pengetahuan pedagogi mereka.

\section{Perbincangan Kajian}

Pada bahagian perbincangan dapatan ini, pengkaji menghuraikan dengan lebih terperinci dan jelas mengenai dapatan kajian mengikut persoalan kajian. Pengkaji membincangkan tentang aktiviti-aktiviti pembangunan profesionalisme dan elemen-elemen berkaitan kajian empirikal seperti sikap, efikasi kendiri, kebimbangan matematik dan pencapaian pelajar.

\section{Perkaitan konseptual kajian}

Dalam bab 2, kerangka konseptual kajian ini menurut Kabilan dan Kasthuri (2012), menggariskan pelbagai elemen berdasarkan analisis dan pemahaman mengenai data yang mempunyai tiga peringkat dalam pembangunan profesionalisme guru matematik seperti perancangan dan pembangunan; pelaksanaan dan pembangunan yang melibatkan guru; dan menilai dan memperkayakan pengalaman dan pertumbuhan profesional guru. Ketiga-tiga tahap ini, jika dibina dengan baik dan dilaksanakan dengan cekap, dapat menyebabkan penyatuan semula pengetahuan dan amalan guru yang bermakna dan berguna, serta meningkatkan budaya profesional mereka, yang seterusnya dapat menyumbang kepada perubahan sekolah, pembaharuan sekolah dan peningkatan prestasi sekolah. Jika dirujuk semula dalam peringkat perancangan dan pembangunan, elemen masa dan tempat menjadi faktor sesuatu program pembangunan profesionalisme itu meninggalkan kesan yang positif kepada guru matematik sekolah rendah. Menurut Aldahmash et al. (2019), tidak terdapat kesan yang signifikan terhadap persepsi guru matematik dan sains mengenai perkaitan atau kegelisahan mereka tentang integrasi STEM. Ini adalah kerana penyertaan mereka dalam program pembangunan profesionalisme adalah selama enam hari. Pernyataan ini disokong oleh Thurm dan Barzel (2020), walaupun kajian mereka dilaksanakan selama enam bulan untuk pengintegrasian teknologi, tempoh masa yang dicadangkan adalah lebih lama agar keberkesanan program pembangunan profesionalisme dapat menunjukkan kesan yang positif kepada guru matematik sekolah rendah.

\section{Keperluan guru}

Begitu juga elemen keperluan guru, pendidikan STEM untuk murid-murid sekolah rendah masih pada peringkat sederhana (Baker \& Galanti, 2017; Aldahmash et al., 2019, Aydin, 2020; Estapa \& Tank, 2017). Oleh itu, pihak penganjur perlu melihat keperluan guru sebelum merancang sesuatu program. Menurut Aydin (2020), terdapat banyak keperluan untuk latihan bersama guru matematik sekolah rendah untuk belajar integrasi amalan STEM, peningkatan pedagogi kecekapan guru yang terdiri daripada pengetahuan kandungan, kontekstualisasi dengan masalah kehidupan sebenar, peningkatan penggunaan teknologi dalam bilik darjah dan menghasilkan penilaian alatan. Hal ini selari dengan pendapat Barham (2020), yang secara konsisten menggariskan keutamaan bagi keperluan pembangunan profesionalisme 
dari sudut pandangan guru matematik menunjukkan keperluan yang berkaitan dengan pembuangan produktif, diikuti dengan penaakulan adaptif, pemahaman konsep, kecekapan strategik, dan diakhiri dengan kesan kelancaran prosedur.

\section{Perkaitan antara pembangunan profesionalisme dengan sikap, efikasi kendiri dan pencapaian pelajar}

Sikap adalah salah satu faktor yang boleh mempengaruhi minat guru untuk mengajar subjek tertentu sebagai tambahan kepada pencapaian akademik pelajar (Aldahmash et al., 2019), justeru pembelajaran murid secara langsung dipengaruhi oleh amalan pengajaran guru (Tan-Adalla \& Ballado, 2016). Individu yang bertanggungjawab dalam menentukan kejayaan suatu pembaharuan adalah guru (Umi Nadiha et al., 2016). Walaupun banyak kajian membuktikan pendekatan pengajaran yang berkesan adalah berpusatkan murid, guru masih selesa menggunakan kaedah konvensional yang berpusatkan guru (Callingham et al., 2016; Hashweh, 2016; Wong et al., 2019). Setiap guru perlu mempunyai Pengetahuan Isi Kandungan yang mantap dan Pengetahuan Pedagogikal Isi Kandungan. Kemahiran ini diperolehi daripada latihan di Institusi Perguruan dan di universiti. Kemahiran ini menjadikan para guru dapat mengetahui perkembangan kanak-kanak dan mengaplikasikan kemahiran tersebut mengikut perkembangan kognitif murid. Sebaliknya, guru yang tidak menjalani latihan formal didapati kurang berkesan dalam mengendalikan pengajaran dan pembelajaran (Wong et al., 2019).

\section{Kesimpulan}

Secara jelas, dapatan dilihat bahawa pembangunan profesionalisme guru matematik sekolah rendah memberi kesan yang besar terhadap keperluan guru atau pencapaian pelajar bukan sahaja dalam bidang matematik bahkan dalam semua bidang ilmu. Transformasi daripada guru-guru diperlukan untuk peningkatan kualiti pengajaran dan pembelajaran di sekolah. Oleh itu, Pelan Pembangunan Pendidikan Malaysia 2013-2025 dirangka supaya matlamat jangka panjang dalam memartabatkan sekolah terbaik dunia menjadi kenyataan. Dengan adanya tinjauan penilaian terhadap aspek-aspek yang berkaitan dengan pembangunan profesionalisme guru matematik sekolah rendah dari pelbagai negara ini, pengkaji yakin kualiti pencapaian guru serta pendidikan pelajar dapat ditingkatkan melalui proses penambahbaikan sistem dan kemahiran yang berkaitan. Seperti mana negara-negara maju berupaya menganjurkan program yang memberi impak positif kepada guru untuk menghubungkaitkan ilmu matematik dalam kehidupan seharian pelajar, Malaysia juga diharap mampu berdaya saing setanding kemahiran serta kehebatan mereka. Ia juga tidak hanya tertumpu kepada peningkatan mutu dalam proses pendidikan sahaja, individu pelajar itu sendiri perlu berusaha dalam membentuk personaliti yang positif kerana keupayaan penyelesaian masalah saling berkait dengan sikap, kebimbangan, efikasi kendiri dan pencapaian pelajar itu sendiri.

\section{Rujukan}

Alamri, N.M. (2020). The Implementation of the Lesson Study Strategy in Teaching Mathematics: Teachers' Perspectives. Education Research International, 1.

Aldahmash, A.H., Alamri, N.M., Aljallal, M.A. \& Bevins, S. (2019). Saudi Arabian science and mathematics teachers' attitudes toward integrating STEM in teaching before and after participating in a professional development program. Cogent Education, 6 (1), https://doi.org/10.1080/2331186X.2019.1580852

Aydin, G. (2020). Prerequisites for elementary school teachers before practicing STEM education with students: A case study. Eurasian Journal of Educational Research, 88, 1-40.

Baker, C.K. \& Galanti, T.M. (2017). Integrating STEM in elementary classrooms using model-eliciting activities: responsive professional development for mathematics coaches and teachers. International Journal of STEM Education, 4(1), 1-15.

Barham, A.I. (2020). Exploring in-service mathematics teachers' perceived professional development needs related to the strands of mathematical proficiency (SMP). Eurasia Journal of Mathematics, 
Science and Technology Education, 16(10).

Biccard, P. (2019). The professional development of primary school mathematics teachers through a design-based research methodology. Pythagoras - Journal of the Association for Mathematics Education of South Africa, 40(1), 1-10.

Estapa, A.T. \& Tank, K.M. (2017). Supporting integrated STEM in the elementary classroom: a professional development approach centered on an engineering design challenge. International Journal of STEM Education, 4(1).

Fulton, E.W., Wickstrom, M.H., Carlson, M.A. \& Burroughs, E.A. (2019). Teachers as Learners: Engaging Communities of Learners in Mathematical Modelling Through Professional Development. t.tp: Springer International Publishing. http://dx.doi.org/10.1007/978-3-030-14931$4 \_7$

Hansen, A., Mavrikis, M. \& Geraniou, E. (2016). Supporting teachers' technological pedagogical content knowledge of fractions through co-designing a virtual manipulative. Journal of Mathematics Teacher Education, 19(2-3), 205-226.

Hjalmarson, M.A. \& Baker, C.K. (2020). Mathematics Specialists as the Hidden Players in Professional Development: Researchable Questions and Methodological Considerations. International Journal of Science and Mathematics Education, 18, 51-66.

Miller, A., Gore, J., Wallington, C., Harris, J., Prieto-Rodriguez, E. \& Smith, M. (2019). Improving student outcomes through professional development: Protocol for a cluster randomised controlled trial of quality teaching rounds. International Journal of Educational Research, 98, 146-158. https://doi.org/10.1016/j.ijer.2019.09.002

Robutti, O., Cusi, A., Clark-Wilson, A., Jaworski, B., Chapman, O., Esteley, C., Goos, M., Isoda, M. \& Joubert, M. (2016). ICME international survey on teachers working and learning through collaboration: June 2016. ZDM - Mathematics Education, Jil. 48. t.tp: Springer Berlin Heidelberg.

Saad, N.S., Jemali, M., Zakaria, Z.H. \& Yusof, Q. (2018). Mathematics Pedagogical Standards: A Suggested Model of Instruction in Enhancing the Mathematics Teacher's Quality of Instruction. IOP Conference Series: Materials Science and Engineering, 296(1).

Sharp, L.A., Bonjour, G.L. \& Cox, E. (2019). Implementing the math workshop approach: An examination of perspectives among elementary, middle, and high school teachers. International Journal of Instruction, 12(1), 69-82.

Takahashi, A. \& McDougal, T. (2016). Collaborative lesson research: maximizing the impact of lesson study. ZDM - Mathematics Education, 48(4), 513-526.

Thurm, D. \& Barzel, B. (2020). Effects of a professional development program for teaching mathematics with technology on teachers' beliefs, self-efficacy and practices. ZDM - Mathematics Education, 52(7), 1411-1422. https://doi.org/10.1007/s11858-020-01158-6

Viseu, F., Martins, P.M. \& Leite, L. (2020). Prospective primary school teachers' activities when dealing with mathematics modelling tasks. Journal on Mathematics Education, 11(2), 301-318.

Warwick, P., Vrikki, M., Vermunt, J.D., Mercer, N. \& van Halem, N. (2016). Connecting observations of student and teacher learning: an examination of dialogic processes in Lesson Study discussions in mathematics. ZDM - Mathematics Education, 48(4), 555-569. 